
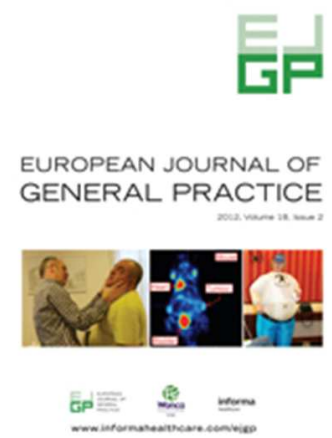

\title{
Termination of Pregnancy: Attitudes and Clinical Experiences of Irish GPs and GPs-in-training
}

\begin{tabular}{|r|l|}
\hline Journal: & The European Journal of General Practice \\
\hline Manuscript ID: & EJGP-2012-0022.R2 \\
\hline Manuscript Type: & Original Research \\
\hline Keywords: & $\begin{array}{l}\text { Health ethics < Operational domain, Cross-sectional designs < Research } \\
\text { Methodology, General practice/family medicine, general < Clinical domain, } \\
\text { Family planning and obstetrics < Clinical domain, Health care organisation } \\
\text { and management < Operational domain }\end{array}$ \\
\hline \multicolumn{2}{|l}{} \\
\hline
\end{tabular}

SCHOLARONE ${ }^{\text {M }}$

Manuscripts 
ABSTRACT

Background: Termination of Pregnancy (ToP) is currently illegal in Ireland. In 2010, more than 4000 women travelled from Ireland to the UK for a ToP.

Objectives: The aims of this study were to assess the attitudes and clinical experiences of Irish General Practitioners (GPs) and GPs-in-training (GPRs) towards ToP.

Methods: A postal survey was sent to $500 \mathrm{GPs}$ in Ireland. An internet-based survey was sent to 244 GPRs. Quantitative and qualitative analysis was performed.

Results: Overall response was $44 \%$. Four groups of doctor's opinions could be identified: [A] abortion can never be allowed (10\%), [B] abortion can be allowed in limited circumstances (25\%), [C] abortion should be available to all women (51\%) and [D] no definite opinion (14\%). Doctors in groups A and B were older and more often Catholic. Of doctors in group C, $66 \%$ indicated an upper gestational limit of maximum 16 weeks. More than $40 \%$ of all respondents had at least one consultation specifically dealing with ToP within the past six months and $43 \%$ agreed with the statement that women's health suffers due to the travel related to ToP.

Conclusion: Most responding GPs and GPRs (75\%) support the provision of ToP in Ireland in certain circumstances. The qualitative analysis of this survey showed that the terms pro-life and pro-choice inappropriately describe the spectrum of opinions. This study highlights clinical situations in which women's health may be adversely affected due to the requirement to travel for ToP.

Key words: Termination of pregnancy, abortion, general practice 
KEY MESSAGE(S)

- A majority (75\%) of Irish GPs and GPs-in-training responding to a postal survey support the provision of termination of pregnancy (ToP) in certain situations

- This study highlights clinical situations in which women's health may be adversely affected because of the requirement to travel for ToP 


\section{INTRODUCTION}

Abortion laws vary greatly throughout Europe. Most European states permit abortion if requested; though impose a gestational limit, ranging from 12 to 16 weeks. Many states also allow for abortion over this gestational limit if specific maternal or foetal factors are present (1). In Malta, abortion is prohibited. Poland allows abortion in cases of severe foetal anomaly, pregnancy as a result of a criminal act or if a woman's life or health is endangered. Luxembourg, Cyprus, Finland and the UK include legal and socio-economic restrictions. In all other EU member states, termination of pregnancy (ToP) can be performed in early pregnancy on a woman's request $(2,3)$. Women from Malta and Poland who choose to have an abortion must travel to other countries to avail of abortion services.

In the Republic of Ireland, abortion has been illegal since 1861. This standing changed in 1992, when a 14-year old rape victim, at risk from suicide, was prevented from leaving Ireland for a ToP by a High Court injunction (4). On appeal, the Irish Supreme Court held that a woman had a right to abortion if there was a real and substantial risk to her life, as distinct to her health, including a risk from suicide. This was called 'The X Case.' Subsequent referenda in 1992 and 2002 attempted to remove suicide as a ground for abortion but were rejected by the Irish electorate. The $X$ Case ruling remains the only legal basis for abortion in Ireland, yet it is unknown if any abortion has taken place in the past twenty years. In 2010, The European Court of Human Rights found that Ireland had violated the European Convention on Human Rights by failing to decide when a woman can qualify for a legal abortion under Irish law.

The number of abortions performed in the UK in 2010 on women who reported residence in the Republic of Ireland was 4402 (5). It is unknown how many women travel 
annually to mainland Europe for ToP. A recent paper on the incidence and trends of induced abortion worldwide show that abortion rates in Ireland are amongst the lowest in the world, clearly related to the restrictive abortion laws (6).

We do not know how many of these women attend their General Practitioner (GP) before or after travelling for ToP. Neither Irish GP attitudes towards ToP nor their clinical experiences in dealing with these women have been studied previously. Therefore, the aims of this study were: (a) To assess the attitudes towards ToP of Irish GPs, including those in training; and (b) To investigate the clinical experiences of Irish GPs in caring for women who seek advice or have had a ToP. 


\title{
METHODS
}

\author{
Selection of participants
}

There are 2496 GPs registered with the Irish College of General Practitioners (ICGP) and the demographics of this population were used in the analysis. A postal survey was sent to 500 GPs, randomly selected from the membership database of the ICGP in May 2011. The survey was also emailed to each of the 244 GP Registrars (GPRs) working in Ireland in May 2011.

The GPRs were contacted through each of the thirteen training schemes and the demographics of this group were provided by ICGP. The survey was anonymous, and confidential. Data entry was performed using Microsoft Access.

\section{Questionnaire}

Questions were generated based on the specified aims of the study. Closed and open questions were used, with options for free text responses allowing GPs provide detailed qualitative information. The questionnaire was four pages long comprising four sections asking demographical information, assessing attitudes to abortion, analysing prior clinical experiences in dealing with women who have had a ToP and asking respondents for a specific case example. The survey was piloted on a small group of GPs and modified accordingly to improve the qualitative information received.

Analysis

This was a mixed method study and produced quantitative and qualitative research data. For 
quantitative analysis, all variables were categorised, and proportions were compared between groups using the chi-square test. Ordinal categories were compared using the chisquare test for trend. The $p$-value for significance was set at 0.05. Data analysis was performed using SPSS (PASW) version 18.0 for Windows.

For qualitative analysis, answers were transcribed, grouped into themes and underwent content analysis (7) Thematic analysis was subject to review and modified by a second independent researcher to ensure impartiality in the processing of the qualitative data. 


\section{RESULTS}

\section{Respondents}

There was a $44 \%$ response amongst GPs (218/500). The overall male/ female ratio for GPs was 4:5. Five age groups were included: $<30(1),<40(79),<50(70),<60(51)$ and 60 and over (17). Religion was categorised into Catholic and other religion, with $76 \%$ and $24 \%$ in each group, respectively. Of the $24 \%$ who were non-Catholic, $50 \%$ of these were agnostic or atheist, $40 \%$ were of another Christian religion (e.g. Protestant, Methodist) and $10 \%$ were Muslim, Buddhist or Hindu. In terms of gender, males in the study were significantly older than females, but religion was equally distributed. There was no difference in age between Catholics and non-Catholics. Compared to the overall GP population in Ireland (2 496 GPs), the GP sample in this study underrepresented the over 60 group but showed a similar distribution in the other age groups (no significant differences in age distribution when over 60 group was excluded). Overall, $49 \%$ of GPs in Ireland are female, and the sample in this study showed a significant higher number of females (57\%). The response from GPRs was $44 \%$ (107/ 244), and 74\% were female. Eighty percent of the GPRs were Catholic. Nearly $60 \%$ of the GPRs were in their $4^{\text {th }}$ year of training. Compared to the GP group, there were significantly more female GPRs, but no difference in religion was observed.

Table 1 shows the opinions of the 325 respondents. The demographics (gender, religion and age) of the responding GPs, GPRs are shown in Table 2.

\section{Opinions towards ToP}


Opinion groups The opinions of the 325 respondents (GPs and GPRs) could be divided into four groups (Table 1): [A] abortion can never be allowed (10\%); [B] abortion can be allowed in limited circumstances (25\%); [C] abortion should be available to all women (51\%); and [D] no definite opinion (14\%).

Group A (never allowed) comprised 11 respondents who answered Yes to the question 'I believe ToP should never be available to any woman' and 21 respondents who believe that all forms of ectopic pregnancy are the only allowable type of ToP. In fact, 103/ 325 respondents answered Yes to 'ToP should only be allowed in very limited circumstances (such as with a risk to the life of the mother),' but $20 \%$ of this group (21/103) answered No to the subsequent question 'Can ToP ever be morally, legally or ethically justifiable excluding ectopic pregnancy?'

Demographic differences between opinion groups Comparing the demographic differences between the four opinion groups for GPs (Table 2), reveals that Groups C and D were younger compared to the other groups $(p<0.01)$. No significant differences were observed between Group A and Group B. Comparing Group C and D showed a significant higher percentage of females in Group $C(p<0.05)$ and a significant higher percentage of younger age groups in Group D $(p<0.01)$. Groups A and B had significantly more Catholics compared to Group C and D ( $p<0.05)$. Two demographical groupings can be identified based on the similarities in age, gender and religion; Group $[A+B]$ and Group $[C+D]$. The percentage of Catholics was significantly higher in Group $[A+B]$ compared to Group $[C+D](p<0.05)$. Group $[A+B]$ also had significantly more GPs in the older age groups $(p<0.01)$. There were no significant differences between Groups $[A+B]$ and $[C+D]$ in gender distribution. 
The same comparisons between the four groups for the GPRs in terms of gender and Catholic religion showed no significant differences. Similarly, no significant differences were observed between Group $[A+B]$ and $[C+D]$ for the GPRs.

Looking at all GPs and GPRs together showed significant differences in age (older age Group A and Group B, p<0.01) and religion (relatively more Catholics in Group A and Group B, $p<$ $0.05)$.

Gestational age Those who believe that women should be able to have the choice of having a ToP in Ireland (Group C) were specifically asked; 'Up to what gestational age do you think ToP should be permissible?' Of the GPs in this group, 51 (46\%) and 14 GPRs (26\%) felt ToP could be performed up to 12 weeks gestation. Overall, 39\% of Group C respondents indicated ToP could be performed up to 12 weeks and a further $27 \%$ up to 16 weeks. The answers ranged from 4 to 24 weeks, with a median of 16 weeks (Table 3).

Reasons to refuse ToP Group C were asked; 'Are there situations in which you feel a ToP could be refused, despite a woman's choice to have one (not relating to gestational age)?' Those who answered Yes provided text box answers and the main concerns expressed were about capacity, coercion, occurrence of multiple ToPs and the risk of the procedure itself (Table 4).

Limited situations for acceptance of ToP Respondents who did not agree with ToP, but believed there are certain, limited situations when ToP can be acceptable (Group B), were asked to outline these situations. Qualitative analysis highlighted three themes, namely (major) foetal anomalies, maternal illness (mother's life at risk) and in cases of rape or incest (Table 5).

Experiences of General Practitioners with ToP 
Consultations on ToP Ninety-seven percent (211) of GPs and 77\% (82) of GPRs had reported a consultation specifically dealing with termination of pregnancy in the past. Overall, $45 \%$ of the respondents had a consultation within the past six months specifically dealing with ToP. Twenty-two respondents managed a patient who underwent a termination specifically indicated because of severe maternal illness. All but one of these ToPs took place in the UK. The main indications were maternal cancer on chemotherapy, severe cardiovascular disease and severe psychiatric risk post-rape.

Abortifacients The use of illegal abortifacients by women was brought to the attention of $11 \%$ of the respondents. The cases involved medical abortifacients, most of which were sourced on the internet or bought illegally in Ireland.

Health effects of travel Nearly $40 \%$ of the respondents believed that a woman's healthcare suffered because of the requirement to travel for ToP. The main concerns were regarding the physical and psychological (stress) health effects of travelling but also the social and financial effects and how the doctor-patient relationship was affected (Table 6). Specific experiences A free text box allowed recipients 'to share a specific case example, which was either significant to them or, which illustrated an unusual issue relating to ToP that may not be widely apparent to the public or other doctors.' Forty-four (44) GPs and 16 of GPRs shared some information on their experiences. Some of the recurring themes were issues concerning foetal anomalies, asylum seeker situations (who are in a situation where they cannot travel), side effects of the procedure, lack of aftercare and counselling (Table 7). 
DISCUSSION

Main findings

We have surveyed the attitudes of Irish GPs towards ToP for the first time. The response rate of our survey on ToP among GPs (218/500) and GPRs (107/ 244) was 44\% in both groups.

The opinions of the respondents could be divided into four groups: $[A]$ abortion can never be allowed (10\%); [B] abortion can be allowed in limited circumstances (25\%); [C] abortion should be available to all women (51\%); and [D]: no definite opinion (14\%). Most GPs (97\%) and GPRs (77\%) reported a consultation specifically dealing with termination of pregnancy in the past. Overall, $45 \%$ of the respondents had a consultation within the past six months specifically dealing with ToP. A large minority $(40 \%)$ of the respondents believed that a woman's healthcare suffered because of the requirement to travel for ToP.

Usage of abortion services by Irish women

Since The X Case ruling of 1992, approximately 100000 women have travelled from Ireland to Europe or the UK to avail of abortion services (5). Irish GPs manage crisis pregnancy regularly. This study shows Irish GPs are involved in the care of women before and after overseas ToP. More than $90 \%$ of the respondents to this survey indicated they had a consultation with women before or after their ToP.

Spectrum of opinions

Our survey shows that the terms 'pro-life' and 'pro-choice' do not aptly describe the 
spectrum of opinions. However, most respondents would support the provision of ToP in Ireland in specific situations (Group B and C, 75\%), such as with foetal anomalies, substantial maternal illness or in case of rape. Over $50 \%$ would support abortion services in Ireland with gestational limits attached. Compared to the public opinion on abortion, a 2007 poll showed that $60 \%$ of $18-35$ year olds felt abortion should be legalised and a 2010 poll found that $54 \%$ of women felt the government should act to permit abortion (8).

The $24 \%$ of GPs who believed 'that ToP should be allowed, but only in very limited circumstances' (Group B) indicated when a legitimate circumstance for ToP may arise i.e. in cases of foetal anomaly, rape, maternal illness or imminent maternal death.

When the GP indicated to be 'pro-choice' (Group C), 66\% felt ToP should only take place if gestation is less than 16 weeks. Interestingly, $22 \%$ of GPs in this group felt there are situations when ToP can be declined in relation to lack of capacity, when coercion is present or if recurrent requests were evident.

Previous studies have identified physician opinion as an important factor in the broader abortion public debate, particularly where abortion is highly restricted (9). Though Ireland's abortion laws are more restrictive than the UK, Finnie et al., (2006) in the North East of the UK, had a similar percentage (24\%) of GPs 'broadly anti-abortion (10).' Studies of gynaecologist opinions in nations where abortion is restricted have shown varied results reflecting the differing questions asked in the surveys; e.g. $51 \%$ of Polish gynaecologists were against abortion, but $77 \%$ of Brazilians gynaecologists were in favour of liberalization of abortion laws $(11,12)$. A qualitative study in Mexico City, after legalisation of abortion in 2007, showed that most health professionals agreed that legal abortion should be offered (13). 
Effects of travelling for abortion services on women's health

Respondents offered examples of clinical situations in which the physical, psychological and social health of women who travel abroad for ToP was affected. There is no consensus on the short and long-term psychological effects of abortions (14-16). However, clearly the circumstances that lead a woman to terminate a pregnancy are independently stressful and the additional stress of travel to a foreign country for a termination, adds to this stress. Some of the respondents in our survey expressed these concerns specifically. It has been shown that travel distance is a determinant of whether a woman obtains an abortion and that travel distance is a greater obstacle for less-advantaged women (17).

\section{Limitations}

We feel the mixed method approach adds to the understanding of this contentious issue and that the thematic analysis and addition of case examples emphasises its complexity. Nevertheless, the attitudinal results must be interpreted in the context of the low $44 \%$ response rate in both groups of physicians. The higher percentage of female respondents in the survey of this compared to the overall GP population as well as an underrepresentation of the over-60 age group may have influenced our results. However, we found that religion rather than age or gender was the more important predictive factor.

Implications

This paper suggests that a majority of Irish GPs might support the government in legislating 
for The X Case decision, i.e. that abortion in limited circumstances should be permitted in Ireland. Of the GPs surveyed, 9\% have dealt with patients with 'real and substantial risk' to their lives that had to travel abroad for ToP. This finding potentially contravenes the Supreme Court decision of 1992. Furthermore, examples of illegal medical abortions being performed were given.

The finding that inter-country travel can have negative health effects has not been studied previously. We would recommend further research in a European context on those women who travel to other European countries to avail of abortion services.

Conclusion

We hope the results of this study will add to the debate on the legal aspects of abortion in Ireland and beyond. This paper suggests that a substantial part of (future) Irish GPs would support the provision of abortion services, in contrast to current practice in Ireland. Many respondents highlighted the need for improved psychological support for women, before and after the procedure. 


\section{REFERENCES}

1. Abortion Legislation in Europe [http://www.ippfen.org/en/Resources/Publications/Abortion+Legislation+in+Eur ope.htm]

2. Gissler M, Fronteira I, Jahn A, Karro H, Moreau C, Oliveira da Silva M, Olsen J, Savona-Ventura C, Temmerman M, Hemminki E, et al. Terminations of pregnancy in the European Union. BJOG: An International Journal of Obstetrics \& Gynaecology 2012,119:324-32.

3. Pinter B, Aubeny E, Bartfai G, Loeber O, Ozalp S, Webb A. Accessibility and availability of abortion in six European countries. Eur J Contracept Reprod Health Care 2005, 10:51-8.

4. Lysaght C, Whelehan H. In Independent, May 20th. Dublin; 2007.

5. Department of Health: Abortion statistics, England and Wales: 2010. 24 May 2011.

6. Sedgh G, Singh S, Shah IH, Ahman E, Henshaw SK, Bankole A. Induced abortion: incidence and trends worldwide from 1995 to 2008. Lancet 2012, 379(9816):62532.

7. Krippendorff K. Content analysis: an introduction to its methodology. 2nd Edition edition. Thousand Oaks, CA: Sage; 2004.

8. Abortion: Public Opinion. [http://www.ifpa.ie/Hot-Topics/Abortion/PublicOpinion]

9. De Zordo S, Mishtal J. Physicians and abortion: provision, political participation and conflicts on the ground--the cases of Brazil and Poland. Womens Health Issues 2011, 21(3 Suppl):S32-6.

10. Finnie S, Foy R, Mather J. The pathway to induced abortion: women's experiences and general practitioner attitudes. J Fam Plann Reprod Health Care 2006,32:15-8.

11. Szymanska M, Knapp P. Opinions of gynaecologists on prenatal diagnostics in first/second trimester and abortion--ethical aspect. Adv Med Sci 2007, 52:182-5.

12. Goldman LA, Garcia SG, Diaz J, Yam EA. Brazilian obstetrician-gynecologists and abortion: a survey of knowledge, opinions and practices. Reprod Health 2005,2:10.

13. Contreras X, van Dijk MG, Sanchez T, Smith PS. Experiences and opinions of health-care professionals regarding legal abortion in Mexico City: a qualitative study. Stud Fam Plann. 2011,42:183-90.

14. Charles VE, Polis CB, Sridhara SK, Blum RW. Abortion and long-term mental health outcomes: a systematic review of the evidence. Contraception 2008,78:436-50.

15. Munk-Olsen T, Laursen TM, Pedersen CB, Lidegaard O, Mortensen PB. Induced first-trimester abortion and risk of mental disorder. N Engl J Med. 2011,364:3329.

16. Stotland NL. Psychiatric aspects of induced abortion. J Nerv Ment Dis. 2011, 199:568-70.

17. Joyce T. The supply-side economics of abortion. N Engl J Med. 2011, 365:1466-9. 


\begin{tabular}{|c|c|c|c|c|}
\hline \multicolumn{5}{|c|}{ Republic of Ireland } \\
\hline & \multicolumn{4}{|c|}{ Opinion Groups * } \\
\hline & $\begin{array}{l}\text { Group A } \\
\text { Never }\end{array}$ & $\begin{array}{l}\text { Group B } \\
\text { Limited }\end{array}$ & $\begin{array}{l}\text { Group C } \\
\text { Anyone }\end{array}$ & $\begin{array}{l}\text { Group D } \\
\text { No opinion }\end{array}$ \\
\hline All $(n=325)$ & $10 \%(32)$ & $25 \%(82)$ & $51 \%(167)$ & $14 \%(44)$ \\
\hline GPs $(n=218)$ & $11 \%(24)$ & $24 \%(53)$ & $52 \%(113)$ & $13 \%(28)$ \\
\hline GPRs $(n=107)$ & $8 \%(8)$ & $27 \%(29)$ & $51 \%(54)$ & $15 \%(16)$ \\
\hline
\end{tabular}

* Opinion on ToP in the Republic of Ireland:

Group A: 'ToP should never be available to any woman'

Group B: 'ToP should be allowed, but only in very limited circumstances (an example would be 'with a real and substantial risk to the life of the mother').'

Group C: 'ToP should be available to any woman who chooses to have it performed.'

Group D: Those who 'do not have a definite opinion on ToP.' 
Table 2. Demographics (gender, religion and age) of respondent GPs and GP Registrars towards Termination of Pregnancy in the Republic of Ireland

\begin{tabular}{|c|c|c|c|c|c|c|}
\hline & \multirow{2}{*}{$\begin{array}{l}\text { Overall } \\
\text { Group } \\
(\mathrm{n}=325)\end{array}$} & \multicolumn{4}{|c|}{ By Opinion Groups * } \\
\hline & & & $\begin{array}{c}\text { Group A } \\
(\mathrm{n}=32) \\
\text { Never }\end{array}$ & $\begin{array}{l}\text { Group B } \\
(\mathrm{n}=82) \\
\text { Limited }\end{array}$ & $\begin{array}{c}\text { Group C } \\
(\mathrm{n}=167) \\
\text { Anyone }\end{array}$ & $\begin{array}{c}\text { Group D } \\
(n=44) \\
\text { No opinion }\end{array}$ \\
\hline \multirow[t]{2}{*}{$\%$ Female } & GP & 57 & 50 & 55 & 64 & 43 \\
\hline & GPR & 74 & 75 & 72 & 74 & 75 \\
\hline \multirow[t]{2}{*}{$\%$ Catholic } & GP & 76 & 88 & 89 & 69 & 71 \\
\hline & GPR & 80 & 88 & 79 & 78 & 88 \\
\hline \multirow{5}{*}{$\begin{array}{l}\text { \% In each age } \\
\text { group (GPs } \\
\text { only) }\end{array}$} & $<=30$ & 1 & & 2 & 1 & \\
\hline & $31-40$ & 36 & 25 & 23 & 38 & 61 \\
\hline & $41-50$ & 32 & 29 & 34 & 32 & 32 \\
\hline & $51-60$ & 23 & 38 & 30 & 21 & 7 \\
\hline & $>=60$ & 8 & 8 & 11 & 8.0 & 0 \\
\hline
\end{tabular}

* See definition of opinion groups in Table 1 


\begin{tabular}{|c|c|c|c|}
\hline Question asked: & & $\begin{array}{l}\text { General } \\
\text { Practitioners } \\
(112 * / 113)\end{array}$ & $\begin{array}{l}\text { General } \\
\text { Practice } \\
\text { Registrars } \\
(54)\end{array}$ \\
\hline $\begin{array}{l}\text { 'Up to what gestational age do you think } \\
\text { ToP should be permissible?' }\end{array}$ & $\begin{array}{r}22-24 \text { weeks } \\
20-22 \text { weeks } \\
16-20 \text { weeks } \\
12-16 \text { weeks } \\
<12 \text { weeks }\end{array}$ & $\begin{array}{ll}6 \% & (7) \\
2 \% & (2) \\
25 \% & (28) \\
21 \% & (24) \\
46 \% & (51)\end{array}$ & $\begin{array}{ll}9 \% & (5) \\
8 \% & (4) \\
17 \% & (9) \\
40 \% & (21) \\
26 \% & (14)\end{array}$ \\
\hline $\begin{array}{l}\text { 'Are there situations in which you feel a } \\
\text { ToP could be refused, despite a woman's } \\
\text { choice to have one (not relating to } \\
\text { gestational age)?' }\end{array}$ & $\begin{array}{c}\text { Yes } \\
\text { No }\end{array}$ & $\begin{array}{ll}22 \% & (25) \\
78 \% & (83)\end{array}$ & $\begin{array}{ll}28 \% & (15) \\
72 \% & (38)\end{array}$ \\
\hline
\end{tabular}

* One non-respondent to this question 


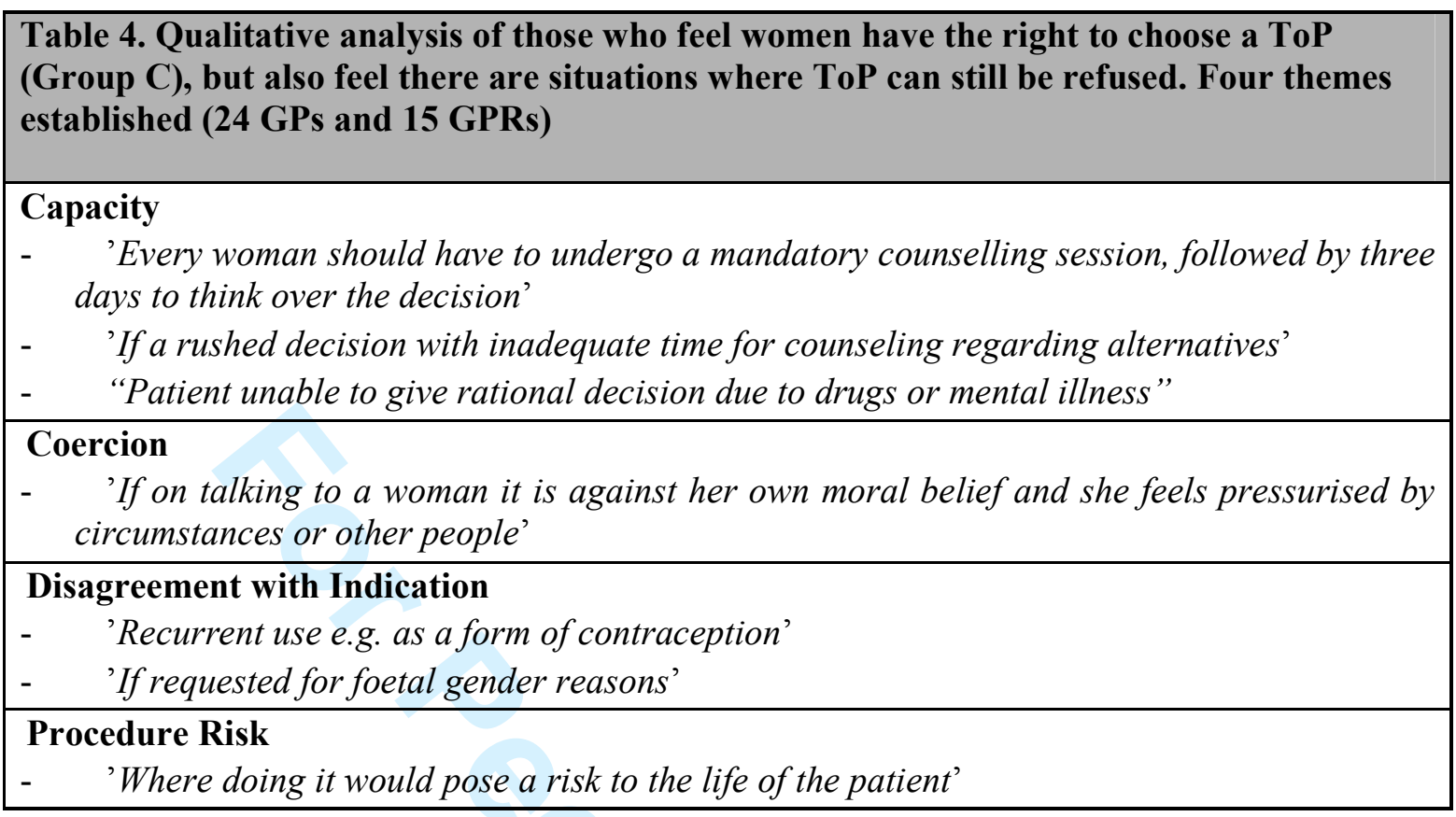


Table 5. Qualitative analysis of those who are against abortion, but also feel it can be allowed in very limited circumstances (Group B). Themes and quotes of when ToP can be performed, taken from 53 GPs and 29 GPRs

Foetal Anomalies (31 mentioned)

- $\quad$ 'Anencephaly, Patau syndrome, Edward's and other syndromes incompatible with life diagnosed antenatally'

'With congenital malformation where they are not compatible with life (will die at birth or before)'

\section{Maternal Illness (45 mentioned)}

- $\quad$ 'To allow for administration of teratogenic medication such as chemotherapy. Very significant abuse or psychiatric cases. Where risk to mother is considered too great: e.g. pulmonary hypertension, mitral valve stenosis and other cardiac abnormalities" "Mother's life at risk'

Rape or Incest (31 mentioned)

- $\quad$ 'Pregnancy arising from sexual assault/ rape' 
Table 6. Qualitative Analysis of those who feel a woman's health suffers specifically because of the requirement to travel overseas for ToP. Examples grouped into five themes (77 GPs and 41 GPRs)

\section{Physical health effects from travelling}

- '... came back from UK- saw her and transferred her to hospital with septicaemia- she died. No follow up. This occurred over 20 years ago.'

- 'Many women do not attend for aftercare with their Irish GP as they are ashamed or embarrassed and often present too late with infection/ bleeding etc.

\section{Psychological health effects from travelling}

- 'Stress of travelling, follow up, post op infection. Psychological effects-dealing with abortion in aftermath, secrecy regarding planning trip.'

- 'Emotionally, psychologically- the feeling of doing it covertly and making provision for family remaining at home.'

- 'Poor supports afterwards as "taboo". Increased guilt as felt doing something illegal more stressed with having to leave country at a very difficult period in life.'

- 'The embarrassment, loneliness and secrecy attached to travel are added burdens on the expectant mother'

\section{Social health effects from travelling (financial, isolation and family)}

- Finances:

- 'Some have not travelled for financial reasons and regretted it.'

- 'People can't always afford and have borrowed money.'

- Isolation:

- 'Burden of financial pressure often leading to having to travel alone.'

- 'Social isolation in emotionally challenging situation.'

- Family:

- 'Social ill-health due to compromised relationship(s) with GP/ friends/family due to knowledge of her having had an abortion, or compromised relationship due to the woman with-holding this knowledge from others.'

\section{Doctor-patient relationship}

- 'Limited psychological support after TOP. Negative view of Irish Healthcare as a result, leading to damaged doctor/ patient relationship.'

\section{Impairment of inter-doctor communication}

- 'Lack of follow up and medical liaison between doctors in the case of suicidal woman was a huge problem.'

- 'Unknown clinic and clinicians in UK, lack of continuity of care.' 


\section{Table 7. Qualitative analysis of specific case examples given by GPs and GPRs.} Examples of 42 GPs and 16 GPRs divided into seven themes

Women travelling abroad with foetal anomalies for abortion

- 'A woman with 2 children who travelled to France to have a ToP because of severe deformities to her foetus- quite late in pregnancy and patient very traumatised after it and bleeding a lot.'

- 'I had a lady who was diagnosed with an anencephalic foetus; she could not afford to travel to UK for a ToP.'

- 'A colleague in practice had a patient who had to travel to England for ToP with a foetal anomaly incompatible with life-very wrong that she had to do this, does not demonstrate a caring attitude of Irish state.'

- 'A woman had a major congenital anomaly detected at 23 weeks, incompatible with lifeshe already had a child and was a carer for her husband with a major chronic disease. It caused chaos that she had to leave the country and made a mockery of the law in this state.'

Asylum seekers who want to travel for ToP

- 'Asylum seeker who was pregnant as a result of rape in her home country came to Ireland believing she would be able to have an abortion. Her status as Asylum Seeker precluded her from travelling abroad without permission of the Minister for Justice. She felt let down by doctors in Ireland, believing they refused to help her.'

Side effects of ToP relating to psychological symptoms of guilt, regret and depression

- 'Most women very well post event- some suffer from regrets but appropriate counselling can alleviate same.'

- 'One woman who had ToP at young age was haunted by guilt and depression at having had a TOP.'

\section{Availability of abortifacients in Ireland}

- 'Patient requesting name of medicines which could be used for early ToP... Money prohibitive to her travelling to U.K for ToP-was exploring internet options.'

- 'I have had two patients sourcing their own agents for medical abortion who presented to the surgery as 'early miscarriage' requesting referral for ultrasound; significant trauma to both women relating to fear of prosecution, inappropriate expectations of outcome, for one woman there were significant complications requiring hospitalisation which she initially refused as her partner was a medical professional and she feared ramifications of discovery.'

\section{Inappropriate aftercare in Ireland}

- 'Patient admitted to hospital with anaemia and endometritis 2 weeks after ToP-highlights total lack of aftercare/ advice and perception of inaccessibility to services in Ireland as patients often do not wish to disclose that they have had ToP.'

\section{Importance of counselling}

- 'The issue I believe that is important is in the follow up of these patients. My experience to date leads me to believe follow up is not properly organised or patients do not follow up themselves.' 
- 'Crisis Pregnancy Programme initiative was very useful: 3 free visits to GP (2 before and one follow up visit after ToP slowed down the process for the patient and have her more time to consider options.'

\section{General Comments}

- '...I personally feel I would never have an abortion and from a personal moral point of view I am completely against abortion. However in my professional role, I feel that every woman deserves the right to choose.'

- 'I have very strong opinions as to the value of ToP: a/ I have never met a woman who regrets having a particular baby. b/ I am frequently, at least weekly, involved in patching up woman's lives who have had ToP. c/ I am discretional in my counselling style in all cases of crisis pregnancy, encouraging women to have the baby for the reasons outlined above.'

- 'I worked in the UK for 6 years. At times ToP was used as a form of contraception, which I found annoying at times but I still felt it was a woman, 's right to choose. I have found it difficult at times since returning to Ireland, as there is such stigma and secrecy surrounding the issue. I work in a deprived area of North Dublin.'

- ' 'Recent consultation for MAP. Second such consultation for that patient in 1 year. History of ToP X 4. Refuses regular contraception. Ethical dilemma for me.' 